\title{
II
}

\section{A PEDAGOGIA DA ALTERNÂNCIA COMO POSSIBILIDADE AO DESENVOLVIMENTO DO PROEJA EM UMA ESCOLA AGRÍCOLA*}

\author{
Gláucia Maria Ferrari ${ }^{1}$
}

A história oficial da Educação de Jovens e Adultos (EJA) possui estreitas relações com o lugar social reservado aos pobres (ARROYO, 2005). A partir dessa perspectiva, compreende-se que o Programa Nacional de Integração da Educação Profissional com a Educação Básica na Modalidade de Educação de Jovens e Adultos (Proeja) se configura como uma importante política destinada a essa modalidade de ensino, pois sua implementação se deu sob a perspectiva de inclusão de milhões de jovens e adultos trabalhadores, historicamente excluídos, nos processos de escolarização básica e na luta pela garantia do direito à educação pública, gratuita e de qualidade.

Apesar de não representar a primeira ou única ação que vise a elevação da escolaridade dos jovens e adultos articulada à formação profissional, a relevância do Proeja se deve ao resgate da possibilidade de integração curricular entre a Educação Profissional e a Educação Básica à inserção do público de EJA nas instituições federais de ensino, tidas como um espaço de excelência no contexto educacional brasileiro, mas que, até o advento do Programa, não possuíam como público tradicional os jovens e os adultos trabalhadores ${ }^{2}$.

Ao cabo de dez anos de sua implantação nas instituições federais, pode-se perceber um cenário de avanços e contradições, requerendo reflexões no que se refere ao real sentido do desenvolvimento do Programa. Dentre os

\footnotetext{
*DOI - 10.29388/978-65-86678-41-3-0-f.43-60

${ }^{1}$ Pedagoga, mestre e doutoranda em Educação pela Universidade Federal Fluminense (UFF). Membro do Núcleo de Estudos e Documentação em Educação de Jovens e Adultos (Nedeja) da UFF. Professora e Técnica em Assuntos Educacionais efetiva do Instituto Federal do Espírito Santo (Ifes) - Campus de Alegre. Experiência profissional em Educação Profissional, Formação Inicial de Professores e Educação de Jovens e Adultos.

${ }^{2}$ O Proeja foi criado pelo Decreto $n^{\circ} 5.478 / 2005$ e reformulado pelo Decreto ${ }^{\circ}$ 5.840/2006, cujo texto estabelece o dever das instituições federais de disponibilizar ao Programa, no mínimo, dez por cento do total das vagas de ingresso da instituição. Quanto à formação integrada, esta havia sido proibida pelo Decreto $n^{\circ} 2.208 / 97$ e resgatada pelo Decreto $n^{\circ} 5.154 / 04$ em resposta às pressões de educadores e pesquisadores da área da educação, dos movimentos sociais e das forças progressistas da sociedade brasileira.
} 
avanços, destaca-se a garantia de acesso de jovens e adultos a essas escolas, as segurado pelo Decreto n ${ }^{\circ} 5.840 / 2006$ e fortalecido pela lei de criação dos Institutos Federais (Lei $\mathrm{n}^{\circ} 11.892 / 2008$ ), que estabelece como primeiro objetivo dessas instituições, a função de ministrar educação profissional técnica de nível médio, prioritariamente na forma de cursos integrados, para os concluintes do ensino fundamental e para o público da educação de jovens e adultos ${ }^{3}$. Ademais, em seus anos iniciais, o Proeja recebeu significativos investimentos de ordem financeira convertidos na oferta de cursos de especialização e na indução de formação de grupos de pesquisas interinstitucionais que reunia pesquisadores de diversas instituições.

Entretanto, o Programa enfrenta desafios que dificultam seu desenvolvimento e colocam em risco a sua continuidade. A necessária formação continuada dos professores que lidam com o Proeja sem nunca antes terem se envolvido com a modalidade de EJA; a concretização de um currículo que integre a Educação Profissional com o ensino médio e respeite as especificidades do público de EJA; a resistência ao Programa fundamentada em uma visão preconceituosa da EJA; a reorganização da prática pedagógica considerando o perfil dos estudantes; a implementação de propostas de formação que contribuam, para além da garantia de acesso, com a permanência dos estudantes e conclusão dos cursos, são alguns dos desafios que permanecem guiando as ações do Proeja no âmbito das escolas federais.

O grave problema da evasão afeta diretamente o desenvolvimento e a continuidade de oferta de vagas no Programa nessas instituições, sendo a modalidade que apresenta o maior índice de evasão dentre as ofertadas (24\%) (BRASIL, 2014, p. 27).

A interrupção do investimento de recursos de ordem técnica e financeira também integra o conjunto de desafios, tendo sido verificado que as ações dessa natureza se restringem ao período de 2006 a 2011. Ou seja, desde o ano de 2011 o Governo Federal não desenvolve ações relacionadas ao PROEJA, o que sugere sua estagnação por parte dos órgãos responsáveis.

Esse cenário revela o risco de descontinuidade do Programa ou, pelo menos, o seu desprestígio atual, fato que representa um relevante retrocesso considerando, especialmente, as conquistas alcançadas no que se refere à pro-

\footnotetext{
${ }^{3}$ Em 2006, o percentual de vagas relacionadas à EJA nas escolas federais correspondia a 0,36\% do total de vagas. Em 2011, esse percentual subiu para 7,2\% (FRANZOI; SILVA; COSTA, 2013). Entre os anos de 2006 a 2010, em algumas regiões brasileiras, o Programa apresentou "percentuais muito além de 10\% do total de matrículas das instituições" (VITORETTE, 2014, p. 21).
} 
dução de conhecimento, ao arcabouço legal e às lutas dos movimentos da sociedade civil preocupados com as questões relacionadas à garantia de direitos e democratização do ensino a todos, independentemente da idade ou de qualquer outra classificação.

$\mathrm{Na}$ contramão desse movimento, algumas instituições federais têm buscado reformular suas práticas educativas na tentativa de abrigar a riqueza e a diversidade da classe trabalhadora (CIAVATTA; RUMMERT, 2010). A Pedagogia da Alternância tem se mostrado como uma alternativa ao desenvolvimento da formação profissional de jovens e adultos do campo, compreendendo-a como facilitadora do conhecimento da realidade dos estudantes, de seus saberes e de suas necessidades.

Nesse sentido, este artigo reflete sobre os resultados de uma pesquisa de mestrado que analisa o desenvolvimento da experiência educativa desenvolvida pelo Instituto Federal Baiano (IFBaiano) - Campus Santa Inês ${ }^{4}$, que articula o PROEJA com a proposta pedagógica da Pedagogia da Alternância.

Nesse estudo de caso, além da pesquisa documental e bibliográfica, foram ouvidos, mediante a utilização de entrevistas semiestruturadas, quatro gestores e seis professores da Instituição, primando-se, dentre os primeiros, por aqueles que possuíam um conhecimento maior sobre o processo de implantação do curso Técnico em Agropecuária no âmbito do Proeja com Alternância.

Quanto aos professores, procurou-se distribuir igualmente a quantidade de entrevistas entre aqueles vinculados às disciplinas da formação básica e da formação profissional, buscando contemplar homens e mulheres, com vínculos institucionais efetivos e temporários.

A escuta dos estudantes se deu pela realização de grupo de discussão ${ }^{5}$, técnica voltada para o conhecimento dos contextos sociais, dos modelos que orientam as ações dos sujeitos e da complexidade de determinadas situações educativas (WELLER, 2006; SANTOS, 2008).

A observação direta de atividades também foi um procedimento metodológico adotado durante a coleta de dados com estes sujeitos. Na perspectiva de Melucci (2005), o pesquisador é por natureza um observador da realidade e de suas representações, e estas, por sua vez, estão a todo tempo em um proces so contínuo de (des)construção.

O material empírico da pesquisa foi organizado e interpretado tendo em vista a técnica de análise de conteúdo, buscando encontrar indicadores que

\footnotetext{
${ }^{4}$ O Campus Santa Inês está localizado na zona rural do município de Santa Inês, distante, aproximadamente, $290 \mathrm{~km}$ da capital do estado da Bahia, Salvador.

${ }^{5}$ Participaram desta atividade um total de dezenove estudantes.
} 
pudessem permitir inferir sobre a realidade, identificando ideias recorrentes, frequentes ou contraditórias percebidas durante o processo (BARDIN, 2009).

$\mathrm{O}$ artigo não se propõe a esgotar todas as questões abordadas na pesquisa, mas apresentar, de forma sintética, alguns aspectos e resultados apresentados na mesma.

\section{Pedagogia da Alternância: percursos, princípios e recontextualiza- ções}

A Pedagogia da Alternância tem sua origem nas Casas Familiares Rurais (CFR) francesas, na década de 1930, tendo sido implementada no Brasil através do Movimento de Educação Promocional do Espírito Santo (MEPES), em 1969. Neste ano foram criadas as três primeiras Escolas Família Agrícolas (EFAs) no Sul do estado do Espírito Santo e, nos anos seguintes, outras sete escolas foram criadas no sul e no norte do estado. Ao longo dos anos a experiência expandiu-se para muitos estados brasileiros, sendo criada, em 1982, a União Nacional das Escolas Famílias Agrícola (Unefab), cuja função refere-se à organização sistêmica, em nível nacional, desse conjunto de instituições.

Trata-se de uma concepção pedagógica que consiste em uma forma de organização do ensino escolar que busca conjugar diferentes experiências educativas, distribuídas ao longo de tempos e espaços distintos, visando proporcionar ao estudante que vive na terra e da terra uma formação mais adequada para a vida no campo e em comunidade, que capaz de contribuir significativamente com a transformação das diversas realidades rurais brasileiras (OLIVEIRA, 2014; 2015).

Apoiada em instrumentos pedagógicos que asseguram a articulação e a interação entre a realidade dos jovens e a vida acadêmica, a formação em Alternância se dá em tempos alternados na escola e na comunidade, Tempo escola e Tempo comunidade, que podem ter duração variáveis (uma semana ou quinze dias).

O ponto de partida desse movimento é sempre a realidade do jovem, ou seja, a família e a comunidade e, em seguida, a escola, onde e quando o estudante compartilha e reflete com outros atores os saberes que já possui, mediante os conteúdos científicos. Posteriormente, o estudante retorna à família e à comunidade, quando se propõe a desenvolver atividades de pesquisa na sua realidade, registrando as experiências vivenciadas em atividades agrícolas ou em ações coletivas (movimentos sociais). 
Nesse sentido, as experiências vividas pelos indivíduos em formação possuem maior relevância que o programa estabelecido pela instituição escolar (conteúdos, saberes sistematizados), invertendo

[...] a ordem dos processos, colocando em primeiro lugar o sujeito que aprende, suas experiências e seus conhecimentos, e, em segundo lugar, o programa. O jovem ou o adulto em formação não é mais, neste caso, um aluno que recebe um saber exterior, mas um ator sócio-profissional que busca e que constrói seu próprio saber. Ele é sujeito de sua formação, ele é produto de seu próprio saber (GIMONET, 1999, p.44-45).

A formação em Alternância se refere a uma formação integral da pessoa, na qual se associam a formação profissional e a formação geral em um processo dialógico entre a teoria e a prática, entre os conhecimentos científicos e os saberes populares, entre os tempos e os espaços de formação e entre os elementos formadores (a família, os professores, os estudantes e o meio), visando uma formação que possibilite o desenvolvimento sustentável do meio no qual o aluno esteja inserido. $\mathrm{O}$ trabalho como elemento de formação é entendido como a vivência do indivíduo na comunidade, na propriedade rural, tornandose o ponto de partida e de chegada do processo de aprendizagem.

Além das Escolas Família Agrícolas (EFA) e das CFR, existem no Brasil inúmeras instituições e experiências educativas que desenvolvem sua atividade escolar e pedagógica por meio da Pedagogia da Alternância. Esse conjunto de instituições recebe o nome de Centros Familiares de Formação por Alternância (CEFFA) que, em sua maioria, oferecem cursos regulares referentes ao $2^{\circ}$ segmento do Ensino Fundamental possuindo orientação profissional e cursos técnicos de nível médio ${ }^{6}$.

No ano de 2006, o ensino por Alternância desenvolvido pelos CEFFAs obteve do Conselho Nacional de Educação (CNE), mediante a aprovação do Parecer CNE/CEB no 01/2006, o reconhecimento quanto à regularidade da duração do ano letivo. Por muitos anos essas instituições funcionaram como experiência pedagógica, mediante autorização dos órgãos educacionais dos Estados (BEGNAMI, 2013).

${ }^{6}$ São considerados CEFFAs as instituições/experiências educativas: (a) Escolas Famílias Agrícolas (EFAs); (b) Casas Familiares Rurais (CFR); (c) Escolas Comunitárias Rurais (ECOR); (d) Escolas de Assentamentos (EA); (e) Programa de Formação de Jovens Empresários Rurais (Projovem); (f) Escolas Técnicas Estaduais (ETE); (g) Casas das Famílias Rurais (CDFR); (h) Centro de Desenvolvimento do Jovem Rural (CDEJOR) (BRASIL, 2006). 
Essa medida contribuiu com o movimento de disputa do sistema da Alternância em toda a sociedade brasileira, sendo adotado também na oferta de cursos superiores de graduação, considerado por Molina (2012, p. 458) "como uma concreta possibilidade de expansão da educação superior aos sujeitos do campo" 7 .

Algumas instituições federais de ensino, tradicionais na oferta do ensino técnico profissional agrícola, principalmente aquelas originadas das antigas Escolas Agrotécnicas Federais (EAF), também foram buscar na Pedagogia da Alternância uma alternativa para o desenvolvimento regional e estímulo à permanência do jovem no campo, principalmente com vistas ao atendimento dos movimentos sociais e da agricultura familiar (BRASIL, 2009). Essas instituições, atualmente campi dos Institutos Federais de Educação, constituem-se em instituições de ensino que possuem características específicas como o regime de internato, semi-internato e externato, além de componentes curriculares relacionados à produção agropecuária (RODRIGUES, 2000).

O ensino agrícola passou por inúmeras transformações, ao longo de sua história, predominando a implantação do sistema Escola-Fazenda que influencia, ainda nos dias atuais, a organização estrutural e didática da maioria dessas instituições. Esse sistema baseia-se no princípio "aprender a fazer e fazer para aprender", sustentando-se na relação ensino/produção que visa conciliar educação, trabalho e produção. Sua finalidade é proporcionar a vivência da realidade social e econômica da comunidade rural, entendendo o trabalho como um elemento integrante do processo ensino-aprendizagem (BRASIL, 2009).

O processo de discussão em busca da (re)significação do ensino agrícola promovido pela Secretaria de Educação Profissional e Tecnológica (SETEC) no ano de 2009 despertou para a necessidade de compreender que esse ensino "deve permitir ao educando o desenvolvimento de sua capacidade de gerar conhecimentos a partir da prática interativa com a realidade de seu meio" (BRASIL, 2009, p. 35).

Esta perspectiva demanda a necessidade de refletir sobre a construção de propostas curriculares e pedagógicas orientadas para a formação integral da pessoa. Como estratégia a ser adotada pelas instituições, surge a proposta de organizar o currículo e o calendário escolar de forma que facilite o acompanha-

\footnotetext{
7 O Programa de Apoio à Formação Superior em Licenciatura em Educação do Campo (Procampo) é uma iniciativa do Mec/Secadi, que possui como objetivo apoiar e implementar cursos regulares de Licenciatura em Educação do Campo nas instituições públicas de ensino superior do país, utilizando a Pedagogia da Alternância como sistema de ensino.
} 
mento de todas as etapas do processo de produção, utilizando, inclusive, a Pedagogia da Alternância para atender a demanda de públicos específicos.

Existe um movimento crescente no interior das instituições federais de ensino, principalmente dos Institutos Federais, que sinaliza para uma aproximação dos princípios da educação do campo e da expansão da adoção da Pedago gia da Alternância. Os regimentos e regulamentos das instituições federais já preveem a Alternância como possibilidade de metodologia na oferta de cursos, concretizando-se em algumas experiências em todo o país.

Durante o desenvolvimento da pesquisa de mestrado foram encontradas vinte e seis experiências sendo desenvolvidas em dezesseis instituições pertencentes à Rede Federal de ensino com a adoção da Pedagogia da Alternância. Essas experiências se distribuem em todo o território nacional, fazendo-se presentes em quatorze estados brasileiros, sendo concretizadas pelo desenvolvimento de cursos técnicos destinados a egressos dos ensinos fundamental e médio (38\%), cursos técnicos e de formação inicial e continuada (FIC) destinado a jovens e adultos no âmbito do PROEJA (50\%) e cursos superiores de graduação e pós-graduação $(12 \%)$.

As treze experiências relacionadas ao PROEJA encontram-se distribuídas entre nove instituições federais de ensino, dentre as quais, oito Institutos Federais e uma Escola vinculada à Universidade Federal. Nas experiências de PROEJA com Alternância, observou-se a preferência por cursos relacionados às atividades agropecuárias (77\%), ofertados, em sua maioria, na forma integrada com o ensino médio $(70 \%)$, reforçando a concepção de formação integral e humana estabelecida no Documento Base do PROEJA e também na Lei 11.892 de 2008 .

Considerando os princípios do Programa estabelecidos no Documento Base (BRASIL, 2007) e os princípios da Pedagogia da Alternância (GIMONET, 2007), percebe-se que essas modalidades convergem em muitos aspectos, dentre os quais: o desenvolvimento de uma formação profissional integral, a partir de um currículo integrado; a flexibilização e valorização dos diferentes tempos e espaços de formação; a valorização da pesquisa como fundamento da formação, compreendendo-a como requisito para o conhecimento da realidade e de construção da autonomia do sujeito; o reconhecimento do trabalho como princípio educativo; e a vida do sujeito como ponto de partida do desenvolvimento da aprendizagem e espaço de formação.

A articulação entre Proeja e Alternância ainda se apresenta como um movimento incipiente, considerando que as primeiras experiências se deram a 
menos de dez anos nos Institutos Federais Catarinense (IFC), do Pará (IFPA) e de Roraima (IFRR). Por outro lado, a atividade revela-se intensa, visto que somente no período de 2013 a 2015, doze projetos foram iniciados, tendo previsão de oferta de mais um projeto para o ano de 2016 pelo Instituto Federal de Santa Catarina (IFSC).

O panorama traçado permite afirmar que se inicia um processo de adoção da metodologia de Alternância nos cursos desenvolvidos pela Rede Federal, principalmente naqueles que se referem ao PROEJA, demandando a necessidade de aprofundamento e compreensão das questões que envolvem o tema, assim como subsídio para consolidação metodológica de formação profissional em Alternância.

\section{O Proeja no IFBaiano Campus Santa Inês e o diálogo com a Peda- gogia da Alternância}

O Campus Santa Inês iniciou as suas atividades com o PROEJA no ano de 2007, ainda como Escola Agrotécnica Federal. Até então, o campus não possuía experiência com a modalidade de EJA. De maneira geral, a atuação das instituições federais restringia-se ao ensino médio integrado aos cursos técnicos, os quais possuíam como grupos destinatários adolescentes egressos do ensino fundamental.

Entre os anos de 2007 a 2010, a instituição ofertou o Programa, mediante o desenvolvimento de cursos técnicos na forma convencional. Apesar de diversificar as habilitações profissionais e a organização pedagógica dos cursos, aparentemente não houve demanda suficiente para o preenchimento de todas as vagas oferecidas.

A região na qual se insere a Instituição possui altas taxas de analfabetismo e baixas taxas de escolarização. Segundo os dados do IBGE (2010), o município de Santa Inês apresentou altos índices de analfabetismo entre pessoas acima de 15 anos (27,21\%), estando acima da média nacional para a mesma época. A série histórica desse indicador aponta para uma expressiva melhoria, sendo que, no período de 1991 a 2000, o índice de analfabetismo caiu de 52,17\% para 30,78\% (IBGE, 2000).

Nesse sentido, o depoimento dos gestores não credita à ausência de demanda para o público de EJA como causa para a baixa procura pelos cursos, sinalizando para o não envolvimento e a resistência dos docentes ao trabalho 
com o Proeja, atribuídas à sua obrigatoriedade de oferta e à ausência de orientações de ordem prática e operacional por parte do governo federal.

$\mathrm{Na}$ perspectiva desses sujeitos, outro fator que dificulta o desenvolvimento do Proeja na Instituição é a dinâmica utilizada no mecanismo de seleção. O processo seletivo dos estudantes se constituía de provas escritas e redação, niveladas qualitativa e quantitativamente com os outros cursos destinados a adolescentes egressos do ensino fundamental, cujo grau de dificuldade acabava por melindrar os jovens e adultos afastando-os do acesso à instituição. Além disso, esse processo não considerava as particularidades dos jovens agricultores da região, diminuindo a garantia da relação entre o curso ofertado e os interesses dos estudantes.

Quanto à resistência institucional ao Programa, os gestores afirmaram que assumir esse compromisso logo no ano subsequente à sua criação, apesar das orientações pedagógicas e operacionais estabelecidas no Documento Base do Programa a partir de 2007, foi um desafio para o campus, gerando insegurança por parte dos gestores, professores e equipe pedagógica.

Além da baixa procura as primeiras experiências com o Proeja obtiveram altas taxas de evasão e baixas taxas de conclusão que causaram preocupação à equipe gestora do campus. Apesar de não haver dados oficiais sobre as causas que levaram à evasão, os relatos dos gestores deixam evidente a relação existente entre as perdas de alunos e o perfil que os mesmos apresentavam.

Em 2012, o Campus Santa Inês implementou sua terceira e atual experiência com o Proeja, o Curso Técnico em Agropecuária desenvolvido pela Pedagogia da Alternância, proposta que surgiu através de uma atividade de extensão desenvolvida desde o ano de 2008 em parceria com a Rede de Desenvolvimento Social (REDES) em dezesseis comunidades rurais. A parceria desdobrou-se em um projeto de assistência técnica e extensão rural denominado "Mãe Terra: cultivando saberes", que iniciara a organização das comunidades no desenvolvimento de técnicas que visavam à produção agroecológica.

Este projeto fora construído junto com as comunidades rurais no intuito de promover assistência técnica e extensão rural com o viés agroecológico. Primeiramente, buscou-se conhecer a realidade e os anseios das comunidades para depois sintetizá-los em uma proposta. O depoimento dos gestores e professores envolvidos com a atividade mostram que o desenvolvimento desse projeto foi fundamental para a percepção da necessidade de criação do curso PROEJA com Alternância, pois possibilitou maior reflexão sobre as possibili- 
dades de continuidade das ações visando a melhoria de vida nas comunidades envolvidas.

Dessa forma, o curso surge com a proposta de oferecer uma formação profissional que pudesse auxiliar os sujeitos do campo no desenvolvimento da agricultura familiar de forma sustentável, além de contribuir para a elevação da escolaridade. Nessa perspectiva, a iniciativa busca contribuir com o processo de Educação do Campo, que luta por uma educação enquanto direito dos que nele residem, adotando os princípios da Pedagogia da Alternância na compreensão que a mesma seja capaz de conectar mais apropriadamente o tempo de formação na escola (Tempo Escola) e o tempo de formação na comunidade rural (Tempo Comunidade), visando facilitar a contextualização da proposta e evitar a ruptura dos jovens e adultos do campo com seu cotidiano, possibilitando afirmarem-se como sujeitos do processo de construção do conhecimento, assim como sua emancipação/desenvolvimento (SOUZA; NEVES, 2013).

Diante das especificidades do público a ser atendido pelo curso, jovens e adultos agricultores ou que possuíam alguma relação com a atividade agrícola, optou-se pela definição de uma forma de acesso que buscasse detectar nos candidatos a sua relação com as atividades agrícolas e ainda a vontade de realizar o curso. Diferentemente das experiências anteriores com o Proeja, o processo seletivo se baseou na realização de entrevistas, de caráter classificatório, cujos critérios de avaliação tinham como eixo norteador o interesse e aptidão do candidato pelo curso, o perfil socioeconômico dos candidatos, a perspectiva dos candidatos de atuação profissional na área do curso e as expectativas dos mesmos em relação à escolarização e profissionalização.

Tanto os gestores quantos os estudantes afirmaram que, para que o curso possa ter continuidade e qualidade, é de fundamental importância a inserção em edital das características requeridas ao acesso ao curso, pois dessa forma as turmas passariam a ser constituídas por estudantes possuidores de características e interesses comuns, o que traria ao curso maior identidade com a área agrícola e, consequentemente, maior eficácia no que se refere à permanência.

Além do mecanismo e procedimentos de seleção adotados, outro fator que contribuiu com a formação da identidade da turma foi a maneira como o curso foi divulgado. Os depoimentos dos estudantes sinalizam que a instituição realizou um intenso processo de sensibilização nas comunidades, buscando conscientizar os jovens da importância de sua participação. 
Segundo dados da Secretaria Escolar do campus, complementados pelos relatos dos gestores, das trinta vagas ofertadas, todas foram preenchidas, havendo ainda lista de suplência de candidatos.

Ao pesquisar o processo de evasão no PROEJA de outro campus do IFBaiano, Bonfim (2012, p. 63), chama atenção para a relevância de ter uma equipe específica para a divulgação de cursos destinados ao Programa. A autora destaca que esse processo precisa se dar em escolas que oferecem EJA para as últimas séries do ensino fundamental, bem como em sindicatos e associações de bairros e comunidades "a fim de contemplar aqueles que se encontram fora da instituição escolar, aproveitando o momento para mapear as demandas sugeridas pelos indivíduos que não concluíram a educação básica".

Dos trinta alunos ingressantes, vinte e quatro permanecem estudando, encontrando-se em fase de conclusão e realização de Estágio Curricular, o que corresponde a um índice de permanência de $80 \%$, o maior obtido em todas as experiências com o Proeja desenvolvidos pelo campus.

Os professores e gestores participantes da pesquisa são unânimes em afirmar que o perfil dos alunos do Proeja com Alternância é o que mais corresponde ao objetivo do curso e do próprio campus, que seria desenvolver a formação técnica para atuação profissional na área de formação. Os dados dos alunos revelaram que todos são oriundos da zona rural, sendo a maioria composta por pequenos agricultores familiares.

A presença de estudantes ligados ao meio rural, segundo os professores, facilitou o processo de formação. Nas entrevistas, eles relatam que por serem do campo, os estudantes possuem o desejo de aprender conhecimentos que possam ser aproveitados ou repassados em suas comunidades visando a melhoria da qualidade de vida, de produção, de relações sociais, de cultura, etc.

Durante a escuta dos depoimentos dos estudantes no grupo de discussão, foi possível perceber que o fator que mais motiva a permanência no curso é o fato de o mesmo funcionar em Alternância. Na visão desses jovens, a Alternância contribui fundamentalmente com a conciliação entre o trabalho e o estudo, favorece o convívio familiar e, ainda, proporciona a vivência dos conhecimentos desenvolvidos e apreendidos nos tempos de formação na própria realidade do estudante.

O currículo do Proeja com Alternância tem como pressuposto o ensino integrado, ensino médio e Educação Profissional, sob o qual se propõe a organização de itinerários formativos que possibilitem o domínio de conhecimentos técnicos e científicos combinado com uma sólida formação humana, valori- 
zando os saberes que os jovens agricultores tecem em sua trajetória individual e coletiva, na família, na comunidade, e na expressão de seus valores e cultura (SOUZA; NEVES, 2013).

Desta forma, percebe-se que o curso possui como finalidade a formação e preparação de cidadãos para atuação não apenas no mundo do trabalho, mas também na vida em sociedade, envolvendo todos os aspectos e dimensões da vida do sujeito (social, cultural, econômica, etc.). Tal formação se ancora na valorização das realidades e dos interesses dos estudantes e em uma relação coerente entre a prática e a teoria, norteada pelo diálogo, pela aprendizagem investigativa, dinâmica e permanente.

A estrutura curricular do curso apresenta-se na modalidade semipresencial, não seriada, materializa pela organização alternada dos tempos de formação: Tempo Escola e Tempo Comunidade. Esse ciclo de Alternância tem duração de cinco dias, estando interligado e integrado por meio de instrumentos pedagógicos específicos: Plano de Estudo, Caderno da Realidade, Colocação em Comum, Tutoria individual, Visitas Técnicas, Serões, Visitas às famílias e às comunidades e Cursos de formação complementar (IFBAIANO, 2012, p. 20-22).

O curso se estrutura em quatro módulos, estruturados sob os seguintes Eixos Temáticos: Identidades, cultura e cidadania, Meio Ambiente e Sustentabilidade, Organização social e políticas públicas e Trabalho e Economia solidária. Esses, por sua vez, são organizados em Temas Geradores definidos ao longo do módulo a partir das demandas dos estudantes em conjunto com os professores.

Segundo Freire (2014), o Tema Gerador pressupõe uma investigação da realidade da qual se manifesta uma rede de relações que orientam a discussão e a interpretação da realidade. O processo de investigação do Tema Gerador, se realizado por meio de uma metodologia conscientizadora, permite a inserção do homem em uma forma crítica de pensar e ver o mundo.

$\mathrm{O}$ autor defende que os Temas Geradores emergem da experiência, mas não apenas dela. Emergem também de uma reflexão crítica sobre as relações entre os homens e o mundo. Portanto, "investigar o tema gerador é investigar, repitam, o pensar dos homens referido à realidade, é investigar seu atuar sobre a realidade, que é a sua práxis" (FREIRE, 2014, p. 136).

No Tempo Escola as atividades dos estudantes se desenvolvem nos três turnos e envolvem aulas teóricas e práticas, palestras, visitas técnicas, serões de estudo, atividades culturais, entre outras. Durante o Tempo Escola os estudantes ficam alojados na Instituição, sendo ainda subsidiada a sua alimentação 
com quatro refeições diárias. A cada início do Tempo Escola são realizados momentos de contextualização, quando os estudantes socializam as atividades e as questões observadas ou desenvolvidas durante o Tempo Comunidade.

O Tempo Comunidade é o ponto central de um currículo em Alternância, pois é a partir dele que toda a ação educativa e formativa é planejada e desenvolvida. Engloba um conjunto de atividades realizadas pelos estudantes nas comunidades rurais, dentre elas: pesquisas, diagnósticos, projetos, experimentos, visitas etc. Essas atividades são orientadas e acompanhadas pelos professores que devem manter contato direto com as comunidades visando garantir a efetivação da formação.

Com base nos relatos dos sujeitos, pode-se afirmar que a realização efetiva do Tempo Comunidade representa um dos grandes desafios do curso na Instituição, pois requer planejamento integrado das ações de desenvolvimento das disciplinas tanto da formação geral quanto da formação profissional e o envolvimento direto e ativo dos docentes, o que ainda necessita ser melhor trabalhado. Outro fator que limita o acompanhamento desse tempo de formação pelos docentes é o grande número de comunidades rurais envolvidas no curso.

Uma alternativa encontrada para a formação durante o Tempo Comunidade foi o Dia de Campo, que se refere a uma atividade de extensão agrícola que foi incorporado ao currículo do curso como atividade específica desse tempo de formação.

Segundo depoimentos dos sujeitos da pesquisa, o Dia de Campo foi criado no decorrer do curso, durante o desenvolvimento da disciplina de Extensão Rural. Em uma das aulas da disciplina houve um debate sobre as dificuldades do Tempo Comunidade, levantando possibilidades que pudessem melhorar a atuação dos estudantes junto às comunidades rurais. Dessa discussão surgiu a proposta de realizar Dias de Campo nas comunidades, que foi levada à coordenação e incorporada ao curso.

Consiste em um momento mensal, normalmente em dias de sábado, organizado pelos estudantes em conjunto com o coordenador do curso e, às vezes, com algum professor, onde eles pesquisam, previamente, as demandas das comunidades, suas necessidades, e, a partir dos resultados desse diagnóstico, planejam as atividades que mais se aproximem do atendimento às mesmas. Nesse dia, os agricultores daquela comunidade são convidados a participar de oficinas e minicursos realizados pelos estudantes.

O Campus Santa Inês fornece toda a parte operacional e de logística como transporte, equipamentos e recursos necessários, alimentação. As comu- 
nidades contribuem com serviços voluntários, preparo do almoço, divulgação e, principalmente, com a participação ativa de famílias e crianças.

Foi possível perceber que o Dia de Campo favorece a socialização dos saberes que as pessoas da comunidade possuem em relação ao seu cotidiano e permite que os estudantes do Proeja possam colocar em prática seus saberes próprios e os desenvolvidos durante o Tempo Escola. Entretanto, verificou-se que essa atividade, assim como outras referentes ao Tempo Comunidade estão mais relacionadas às disciplinas da formação profissional. A Instituição ainda não conseguiu encontrar uma forma efetiva de envolvimento das disciplinas da formação geral nesse tempo de formação.

\section{Considerações finais}

Compreendendo a importância do Proeja no conjunto de ações e políticas destinadas à EJA no Brasil, o artigo busca retomar alguns dos achados da pesquisa de mestrado que buscou compreender como se dá o diálogo entre o Curso Técnico em Agropecuária desenvolvido pelo IFBaiano - Campus Santa Inês no âmbito do Proeja articulado com a Pedagogia da Alternância, principalmente refletindo sobre os novos caminhos que vem sendo trilhados pelas instituições que compõem a Rede Federal de Educação Tecnológica para sua implementação, bem como o crescente diálogo com a perspectiva da Alternância.

O desenvolvimento da pesquisa possibilitou a compreensão de que a concepção pedagógica da Alternância pode representar uma alternativa ao desenvolvimento do Proeja no campo na medida em que sua dinâmica possibilita ao estudante que trabalha melhores condições de conciliar os estudos com a atividade profissional, contribuindo também com a inclusão dos jovens e adultos do campo neste contexto educativo, a partir de uma formação profissional humana, integrada, e não apenas do alinhamento com as demandas do mercado de trabalho.

Este capítulo se encerra salientando que o sistema da Alternância é uma experiência nova no contexto da Instituição sendo o Campus Santa Inês pioneiro nessa direção e o curso analisado, um projeto experimental. Nesse sentido, registra-se que o planejamento pedagógico, a vivência do Tempo Comunidade por docentes e estudantes, a escolha coletiva dos conteúdos referentes aos temas gerados e a utilização dos instrumentos pedagógicos da Pedagogia da Alternância, não aconteceram como estava previsto no Projeto Pedagógico do Curso analisado. 
A investigação também não deu conta de compreender algumas dimensões da experiência analisada e também dos sujeitos participantes da pesquisa, como, por exemplo, as razões das resistências instituídas no contexto escolar e as perspectivas dos estudantes em relação à elaboração e ao desenvolvimento de projetos de vida e de futuro.

Entretanto, pelo entendimento dos sujeitos participantes da pesquisa e pela observação do cotidiano da formação, pode-se compreender a experiência como exitosa, considerando os bons indicadores de permanência, os resultados de aprovações de estudantes em vestibulares e o engajamento dos estudantes e professores no desenvolvimento do curso.

\section{Referências}

ARROYO, M. G. A Educação de jovens e adultos em tempos de exclusão. In: Construção coletiva: contribuições à educação de jovens e adultos. Brasília: UNESCO, MEC, RAAAB, 2005, p. 221-230.

BARDIN, L. Análise de Conteúdo. Lisboa: Edições 70, 2009.

BEGNAMI, J. B. Estudo sobre o funcionamento dos Centros Familiares de Formação por Alternância no Brasil - CEFFAs. Relatório MEC/SECADI. Brasília, 2013.

BONFIM, S. V. M. da S. A problemática da evasão de estudantes vinculados ao PROEJA IF BAIANO - Campus Guanambi. 2012. 112 f. Dissertação (Mestrado em Educação Agrícola) - Programa de Pós-Graduação em Educação Agrícola, Universidade Federal Rural do Rio de Janeiro, Seropédica, 2012.

BRASIL. Ministério da Educação. Parecer CNE/CEB no 1, de 01 de fevereiro de 2006. Dias letivos para a aplicação da Pedagogia da Alternância nos Centros Familiares de Formação por Alternância (CEFFA). Diário Oficial da União, Brasília, 15 mar. 2006.

. Ministério da Educação. Secretaria de Educação Profissional e Tecnológica. PROEJA - Programa Nacional de Integração da Educação Profissional com a Educação Básica na Modalidade de Educação de Jovens e Adultos. Educação Profissional Técnica de Nível Médio / Ensino Médio. Documento Base. Brasília: MEC, 2007. 
- Ministério da Educação. Secretaria de Educação Profissional e Tecnológica. (Re)significação do Ensino Agrícola da Rede Federal de Educação Profissional e Tecnológica. Documento Final. Brasília, DF, 2009.

. Ministério da Educação. Secretaria de Educação Profissional e Tecno-

lógica. Documento orientador para a superação da evasão e retenção na Rede Federal de Educação Profissional, Científica e Tecnológica. MEC, Brasília, DF, 2014.

CIAVATTA, M.; RUMMERT, S. M. As implicações políticas e pedagógicas do currículo na Educação de Jovens e Adultos Integrada à Formação Profissional. Educação e Sociedade, Campinas, v. 31, n. 111, p. 461-480, abr./jun. 2010. FRANZOI, N. L.; SILVA, C. O. B.; COSTA, R. de C. D. PROEJA E PRONATEC: a dança dos atores entre a formulação e a implementação de políticas governamentais. In: XXVI ANPAE - Simpósio Brasileiro de Política e Administração da Educação, 2013, Recife, Anais..., Recife, Anpae, 2013.

FREIRE, P. Pedagogia do Oprimido. 56 ed. Rio de Janeiro: Paz e Terra, 2014.

GIMONET, J. C. Nascimento e desenvolvimento de um movimento educativo: as Casas Familiares Rurais de Educação e de Orientação. In: Pedagogia da Alternância: Alternância e Desenvolvimento. Salvador, UNEFAB, 1999, p.39-48.

Praticar e compreender a Pedagogia da Alternância dos CEFFAs. Tradução de Thierry de Burghgrave. Petrópolis: Vozes, 2007.

IBGE. Censo Populacional de 2000. Rio de Janeiro: IBGE, 2000.

Censo Brasileiro de 2010. Rio de Janeiro: IBGE, 2010.

IFBAIANO. Campus Santa Inês. Projeto Pedagógico de Curso: Técnico em Agropecuária Integrado ao Ensino Médio na Modalidade de Educação de Jovens e Adultos/PROEJA na Metodologia da Alternância. Santa Inês, 2012.

MELUCCI, A. Por uma sociologia reflexiva. Pesquisa qualitativa e cultura. Petrópolis: Vozes, 2005.

MOLINA, M. C. Legislação Educacional do Campo. In: CALDART, R. S. et al (Orgs). Dicionário da Educação do Campo. Rio de Janeiro: Expressão Popular, 2012, p. 453-459. 
OLIVEIRA, M. M. de. Jovens e Educação no Campo: por uma política de reconhecimento dos movimentos sociais e campesinos. Boletim Observatório Jovem, Niterói, v. 03, p.1-10, 2014.

. Juventude rural de Pedagogia da Alternância. Revista Sodebras, v. 10, n. 113, p.168-173, maio 2015.

RODRIGUES, A. C. A educação profissional agrícola de nível médio: o sistema escola-fazenda na gestão da coordenação nacional do ensino agropecuário - Coagri: 1973 - 1986. 2000. 206 f. Dissertação (Mestrado em Educação) - Programa de Pós-Graduação em Educação, Universidade Federal de Minas Gerais, Belo Horizonte, 2000.

SANTOS, C. O grupo de discussão e os estudos sociológicos em contextos escolares. In: VI CONGRESSO PORTUGUÊS DE SOCIOLOGIA, ASSOCIAÇÃO PORTUGUESA DE SOCIOLOGIA, 2008, Lisboa, Anais..., Lisboa, p. $1-12,2008$.

SOUZA, A. L. V.; NEVES, P. M. Relato da Experiência do IF Baiano Campus Santa Inês, Santa Inês, 2013.

VITORETTTE, J. M. B. A não consolidação do PROEJA como política pública de Estado. 2014. 253 f. Tese (Doutorado em Educação) - Programa de Pós-Graduação em Educação, Universidade Federal de Goiás, Goiânia, 2014.

WELLER, W. Grupos de discussão na pesquisa com adolescentes e jovens: aportes teórico-metodológicos e análise de uma experiência com o método. Educação e Pesquisa, São Paulo, v. 32, n. 2, p. 241-260, maio/ago. 2006. SILVA, T. Tadeu. Documentos de identidade. Belo Horizonte: Autêntica, 1999. 
